\title{
Introduction to Analytics and Decision Support for Green IS and Sustainability Applications
}

\author{
Omar El-Gayar \\ Dakota State University \\ omar.el-gayar@dsu.edu
}

\author{
Arno Scharl \\ MODUL University Vienna \\ scharl@ecoresearch.net
}

\author{
PingSun Leung \\ University of Hawaii at Manoa \\ psleung@hawaii.edu
}

The final report of the World Commission on the Environment and Development, also known as the Brundtland Report, defines sustainable development as "development that meets the needs of the present without compromising the ability of future generations to meet their own needs". Subsequent international efforts such as the Rio de Janeiro Conference in 1992, the publication of Agenda 21, the Rio +5 special session of the United Nations (UN) in 1997, the formation of the World Business Council for Sustainable Development in 1997, and the Rio+20 UN Conference on Sustainable Development can be credited with raising environmental concerns to increase public awareness, serving as an initial focus and impetus for collaboration as well as conflict between government, industry, and academia. The Johannesburg "Plan of Implementation", revealed at the Earth Summit 2002, affirmed commitment by the UN to fully implement Agenda 21. Environmental management systems standards (EMSS) such as ISO 14001 and the European Eco-management and Audit System (EMAS) provide a sound practical basis for environmental management within organizations.

Information systems (IS) support both immediate action and sustainable long-term strategies, helping to address the urgency and scope of environmental problems. This mini-track emphasizes the significant research synergies that exist between IS and environmental management for sustainable development from an organizational as well as a technical perspective. Collaboration and cross-fertilization between these domains can be mutually beneficial and may in fact present unique, timely and socially relevant 'real-world' research opportunities as well as viable public sources of empirical ecological information for interdisciplinary research and application.

The mini-track welcomes research articles and practitioner reports exploring technical and organiza- tional issues pertaining to innovative ways for leveraging information systems and technologies for addressing sustainability issues and research that aim to mitigate the impact of economic development and information technologies on the environment. The minitrack encompasses Green IS, environmental informatics and analytics, sustainable computing, and Green IT. Theoretically founded papers that illustrate the application of analytics, Internet of Things (IoT), cloud computing, information systems and decision technologies in environmental management for sustainability are particularly welcomed. Possible topics include, but are not limited to::

- Agriculture 4.0 and smart agriculture

- Analytics and decision technologies

- Environmental sustainability and decision making

- Environmental knowledge acquisition and management

- Environmental Management Information Systems (EMIS), and Environmental Decision Support Systems (EDSS)

- Green IS

- Green IT

- Environmental cyberinfrastructure

- Environmental communication

- Energy informatics

- Smart agriculture, aquaculture and fisheries

- Technologies for DSS development and environmental applications (e.g., Geographic Information Systems (GIS), information visualization, computational intelligence, IoT, web services, cloud computing, artificial intelligence, agent-based computing, and multiplecriteria decision making). 